\title{
Effects of astragaloside IV on eosinophil activation induced by house dust mite allergen
}

\author{
XIAOYAN GU ${ }^{1}$, DESHENG JIANG ${ }^{1}$, YUWEI WANG ${ }^{1}$, QIANG DU ${ }^{2}$ and JIANKANG CAI ${ }^{2}$ \\ ${ }^{1}$ Department of Respiratory Medicine, The 454th Hospital of Chinese PLA, Nanjing, Jiangsu 210002; \\ ${ }^{2}$ Department of Respiratory Medicine, The Second Affiliated Hospital of Nanjing Medical University, \\ Nanjing, Jiangsu 210011, P.R. China
}

Received December 22, 2011; Accepted March 13, 2012

DOI: $10.3892 / \mathrm{mmr} .2012 .869$

\begin{abstract}
Astragaloside IV (AS-IV) has been noted for its reduction of eosinophilic airway inflammation in a murine model of chronic asthma. To gain a better understanding of the mechanisms involved in this anti-inflammatory phenomenon, the effect of AS-IV on human blood eosinophils was studied in vitro. Eosinophils were isolated from the blood of patients with mild atopic asthma, preincubated with AS-IV for $1 \mathrm{~h}$ and stimulated in the presence or absence of the house dust mite allergen Dermatophagoides pteronyssinus (Der p) 1 for $4 \mathrm{~h}$. The survival of the eosinophils at $48 \mathrm{~h}$ was investigated using trypan blue and the surface expression of CC chemokine receptor 3 (CCR3) and intercellular adhesion molecule-1 (ICAM-1) by the eosinophils was analyzed using flow cytometry. The secretion of cytokines in the supernatants and the chemotaxis of the eosinophils were measured by ELISA and the transwell system, respectively. Der p 1 was found to prolong the survival of the eosinophils. Similarly, the expression of CCR3 and ICAM-1, secretion of interleukin (IL)-1 $\beta$, IL-5, tumor necrosis factor (TNF)- $\alpha$ and the granulocyte macrophage colony stimulating factor (GM-CSF) and transmigration of the eosinophils were increased in the presence of Der $p 1$. However, these inductive effects on the eosinophils were significantly inhibited by AS-IV (50 $\mu \mathrm{g} / \mathrm{ml})$. These findings suggest that AS-IV modulates eosinophil activation and trafficking in response to Der $\mathrm{p} 1$ and may therefore be a useful therapeutic option in eosinophilic asthma.
\end{abstract}

\section{Introduction}

In allergic asthma, the accumulation and activation of eosinophils in the lung tissue are thought to contribute to airway inflammation $(1,2)$, but the mechanisms by which eosinophils accumulate in the peribronchial tissues of the lung are complex.

Correspondence to: Dr Qiang Du, Department of Respiratory Medicine, The Second Affiliated Hospital of Nanjing Medical University, 121 Jiangjiayuan Road, Nanjing, Jiangsu 210011, P.R. China

E-mail: jingshuyue@gmail.com

Key words: eosinophils, asthma, astragaloside IV, house dust mite
They may include an enhanced rate of differentiation and release from the bone marrow, selective adhesion and transendothelial migration (TEM) in response to specific chemotactic mediators and prolonged survival of the eosinophils (3).

Adhesion and TEM are mediated by the binding of leukocyte adhesion receptors to their ligands or counter-structures on the postcapillary endothelium. Intercellular adhesion molecule-1 (ICAM-1) is a significant factor in the regulation of the irreversible steps in the TEM of eosinophils (4). The selective migration of eosinophils from the blood to allergic tissues is achieved via specific eosinophil chemoattractants, including eotaxin (5). CC chemokine receptor 3 (CCR3) is the main chemokine receptor on eosinophils and is an exclusive receptor for eotaxin. An increased level of expression of CCR3 has been observed in asthmatic lungs and linked to the pathogenesis of asthma. The blockade of CCR3 has been shown to result in a reduction of eosinophilic infiltration in animal models of asthma $(6,7)$.

Dermatophagoides pteronyssinus (Der p) 1 is a major mite allergen that increases the incidence of allergic disease (8). In vitro, the allergen activates $\mathrm{NF}-\kappa \mathrm{B}$ in human eosinophils, as shown by the upregulation of the expression of adhesion molecules $(9,10)$ and the production of inflammatory cytokines $(10,11)$, and selectively recruits airway dendritic cells upon the activation of the airway epithelium (12). Furthermore, the recurrent exposure of newborn monkeys to the house dust mite (HDM) aeroallergen has been found to result in the significant recruitment of eosinophils into the airway mucosa (13).

The results of animal studies have shown that genetically modified mice lacking eosinophils are protected from allergen-induced lung injury and asthma. Therefore, the development of effective eosinophil-depleting agents for clinical use is necessary (14). Astragaloside IV (AS-IV), purified from the Chinese medical herb Astragalus membranaceus (Fisch) Bge, has potent immunoregulatory and anti-inflammatory effects. Previously, we (15) and other authors (16) established that AS-IV inhibits eosinophilic airway inflammation in a murine model of chronic asthma. However, the effects of AS-IV on the activation and function of primary human eosinophils in response to the allergen have not been well studied. In the present study, we investigated the effects of AS-IV on the surface molecular expression, cytokine production, in vitro survival and TEM of eosinophils induced by Der $\mathrm{p} 1$. 


\section{Materials and methods}

Chemicals. AS-IV (Fig. 1) was purchased from the National Institute for the Control of Pharmaceutical and Biological Products (purity $>98 \%$; Beijing, China) and was dissolved in DMSO. In all of the experiments, the concentration of DMSO was $0.1 \%(\mathrm{vol} / \mathrm{vol})$.

Human subjects. Patients with mild atopic asthma were recruited from the Database of China Asthma Alliance Jiangsu Branch according to the guidelines of GINA 2006 (17). None of the patients took medication for at least 2 weeks prior to the study, with the exception of the as-needed use of inhaled $\beta_{2}$-agonists. The study was approved by the Jiangsu Province Hospital Ethics Committee and written informed consent was obtained from all of the subjects.

Eosinophil separation and culture. Eosinophils were isolated using negative immunomagnetic bead selection as previously described (10). Briefly, the heparinized blood was diluted 1:2 with phosphate-buffered saline (PBS) at $4^{\circ} \mathrm{C}$ and centrifuged using an isotonic Percoll solution (density $1.082 \mathrm{~g} / \mathrm{ml}$ ). The eosinophil-rich granulocyte fraction was collected and washed twice with cold PBS containing $2 \%$ fetal calf serum (FCS). The cells were then incubated with mouse anti-human CD16 monoclonal antibody (mAb) (Miltenyi Biotech, Bergisch Gladbach, Germany) at $4^{\circ} \mathrm{C}$ for $45 \mathrm{~min}$. CD16-positive neutrophils were depleted by passing the cells through an LS+ column (Miltenyi Biotech) within a magnetic field and CD16-negative eosinophils ( $>98 \%$ purity and $>99 \%$ viability) were collected and resuspended in the culture medium (RPMI-1640 supplemented with $10 \%$ FCS). The collected eosinophils were pretreated with or without AS-IV $(0.5,5.0$ or $50 \mu \mathrm{g} / \mathrm{ml})$. After $1 \mathrm{~h}$, the cells were washed and stimulated in the presence or absence of $10 \mu \mathrm{g} / \mathrm{ml}$ Der $\mathrm{p} 1$ (Indoor Biotech, Charlottesville, VA, USA) for a further $4 \mathrm{~h}$ and the cells and supernatants were collected for further analysis.

Eosinophil survival assay. The eosinophils were resuspended $\left(1-1.5 \times 10^{6}\right.$ cells $\left./ \mathrm{ml}\right)$, aliquoted into $96-$ well culture plates (Corning Costar, Lowell, MA, USA) in triplicate $(100 \mathrm{ml} /$ well) and incubated in $5 \% \mathrm{CO}_{2}$ at $37^{\circ} \mathrm{C}$ for $48 \mathrm{~h}$. Viable and dead eosinophils were counted following the addition of $20 \mu 1$ of trypan blue in a hemocytometer. The number of viable cells is expressed relative to the number of cells seeded at the beginning of the culture and calculated as: percentage of viable eosinophils $=$ (number of trypan blue-negative cells/number of cells seeded) $\mathrm{x} 100$.

Enzyme-linked immunosorbant assay. The supernatants of the eosinophils were collected to measure the levels of interleukin (IL)-1 $\beta$, IL-5, granulocyte macrophage colony stimulating factor (GM-CSF) and tumor necrosis factor (TNF)- $\alpha$ using ELISA kits (Biosource, Carlsbad, CA, USA) according to the manufacturer's instructions.

Flow cytometric analysis. The collected eosinophils were incubated with $10 \mu \mathrm{l}$ of saturating concentrations of the fluorescent-labeled $\mathrm{mAb}$, including fluorescein isothiocyanate (FITC)-conjugated rat anti-human CCR3 (R\&D Systems,

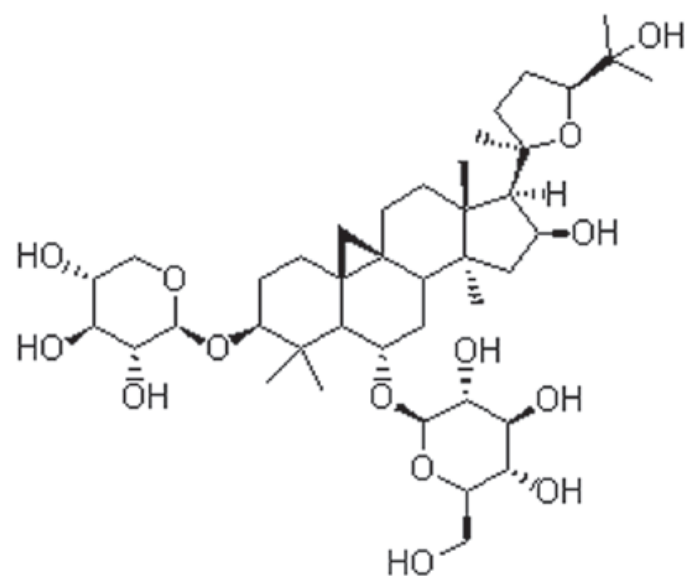

Figure 1. Chemical structure of astragaloside IV.

Minneapolis, MN, USA) and phycoerythrin (PE)-conjugated mouse anti-human ICAM-1 (BD Biosciences, San Diego, CA, USA) $\mathrm{mAb}$ for $30 \mathrm{~min}$ at $4^{\circ} \mathrm{C}$. The cells were then washed with cold PBS and fixed in $1 \%$ paraformaldehyde. The surface markers of eosinophils were then assessed using a FACScan cytofluorometer (BD Biosciences).

Endothelial cell cultures. Human umbilical vein endothelial cells (HUVECs) were isolated and cultured according to the methods described by Muller et al (18), with some modifications. In brief,HUVECs were suspended in RPMI-1640 medium (Life Technologies, Gaithersburg, MD, USA) containing 20\% FCS (Gibco Invitrogen, Carlsbad, CA, USA) and penicillin-streptomycin. The primary cultures $\left(0.5-1 \times 10^{6}\right.$ cells $\left./ \mathrm{ml}\right)$ were seeded in 24-well plates (Corning Costar, Cambridge, MA, USA) coated with human plasma fibronectin and gelatin in $5 \% \mathrm{CO}_{2}$ at $37^{\circ} \mathrm{C}$. The medium was changed daily until $80-90 \%$ confluence was achieved, in 2-3 days. The cells were then passaged in human plasma fibronectin and gelatin-coated transwell inserts ( $5 \mu \mathrm{m}$ pore, Corning Costar). Light microscopy confirmed that the monolayer was confluent. HUVECs were pretreated with $1 \mathrm{ng} / \mathrm{ml}$ IL-1 $\beta$ (Sigma, St. Louis, MO, USA) for $4 \mathrm{~h}$. The monolayer was washed twice with RPMI-1640 medium prior to use.

TEM of eosinophils. TEM assays were performed as previously reported, with some modifications (19). The eosinophils were preincubated with or without AS-IV $(0.5,5.0$ or $50 \mu \mathrm{g} / \mathrm{ml})$ for $1 \mathrm{~h}$ at $37^{\circ} \mathrm{C}$. After being washed with RPMI-1640 medium to remove AS-IV, the cells $\left(1 \times 10^{6}\right)$ were added to the upper chamber of the transwell inserts and either control medium or Der p $1(10 \mu \mathrm{g} / \mathrm{ml})$ was added to the lower chamber. Following incubation for $4 \mathrm{~h}$, the plate was placed on ice. EDTA (50 $\mu \mathrm{l}$; $1 \mu \mathrm{M}$ ) was added to the upper chamber to prevent further transmigration and the transmigrated eosinophil populations were collected. The ratio (\%) of migration was calculated as: (number of migrated cells/total number of cells added into the upper chamber) x 100. The viability of the eosinophils following migration was $>96 \%$ by trypan blue exclusion.

Statistical analysis. The data are presented as the mean \pm standard error of the mean (SEM). The statistical comparison between the groups was carried out using the unpaired 
Student's t-test. $\mathrm{P}<0.05$ was considered to indicate a statistically significant result.

\section{Results}

AS-IV inhibits the Der $p$ 1-induced survival of eosinophils at $48 \mathrm{~h}$. On the basis of the trypan blue dye exclusion method, $7.42 \pm 1.93 \%$ of the control eosinophils (not exposed to Der p 1) were viable at $48 \mathrm{~h}$. In the presence of $10 \mu \mathrm{g} / \mathrm{ml}$ Der $\mathrm{p} 1$, the viability of the cells was more stable, at $21.88 \pm 4.69 \%$ at $48 \mathrm{~h}$ $(\mathrm{P}<0.05$ vs. control cells; Fig. 2), indicating that Der $\mathrm{p} 1$ was effective at preventing the death of eosinophils. To determine the effect of AS-IV on the $48 \mathrm{~h}$ survival of eosinophils, the cell viability assay was performed following pretreatment with AS-IV $(0.5,5.0$ or $50 \mu \mathrm{g} / \mathrm{ml})$. Notably, the percentage of viable cells was significantly reduced only when the eosinophils were pretreated with $50 \mu \mathrm{g} / \mathrm{ml}$ AS-IV ( $<<0.05$ vs. Der p 1-stimulated cells; Fig. 2). Moreover, AS-IV (50 $\mu \mathrm{g} / \mathrm{ml})$ had no toxic effect on the eosinophils, as assessed by the trypan blue exclusion method (data not shown).

AS-IV suppresses the Der p 1-induced release of cytokines by eosinophils. In the culture supernatant, the control eosinophils released low levels of IL- $1 \beta$, IL-5, GM-CSF and TNF- $\alpha$ whereas stimulation with Der $\mathrm{p} 1$ for $4 \mathrm{~h}$ induced the release of these cytokines (all $\mathrm{P}<0.05$ ). Notably, pretreatment with

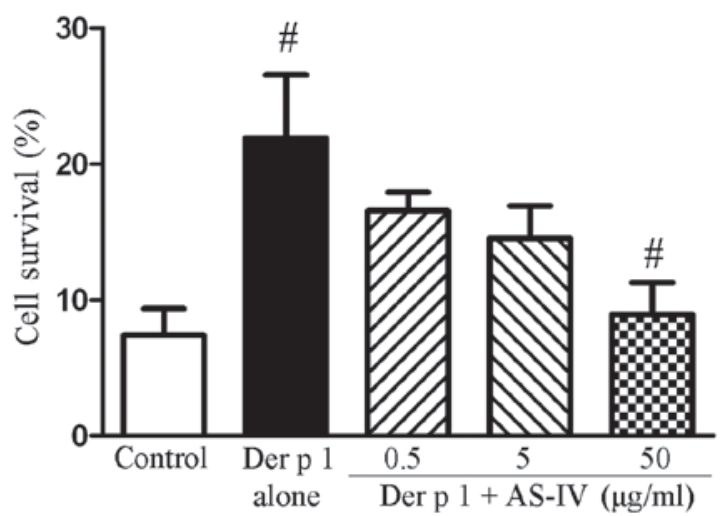

Figure 2. Effect of increasing concentrations of AS-IV on the Der p 1-induced survival of eosinophils. Data are presented as the mean \pm SEM of five independent experiments. ${ }^{\#} \mathrm{P}<0.05$ vs. control cells or Der p 1-stimulated cells. AS-IV, astragaloside IV; Der p 1, Dermatophagoides pteronyssinus 1 .

$50 \mu \mathrm{g} / \mathrm{ml}$ AS-IV markedly inhibited the production of the four cytokines (all $\mathrm{P}<0.05$; Fig. 3).

$A S-I V$ reduces the Der $p$ 1-stimulated expression of CCR3 and ICAM-1 by eosinophils. We investigated the effects of AS-IV on the expression of CCR3 and ICAM-1 by human eosinophils. The application of $10 \mu \mathrm{g} / \mathrm{ml}$ Der $\mathrm{p} 1$ induced the
A

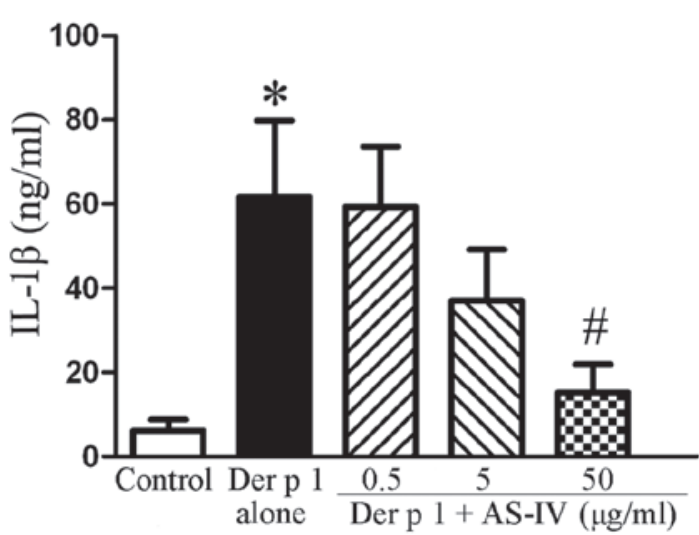

C

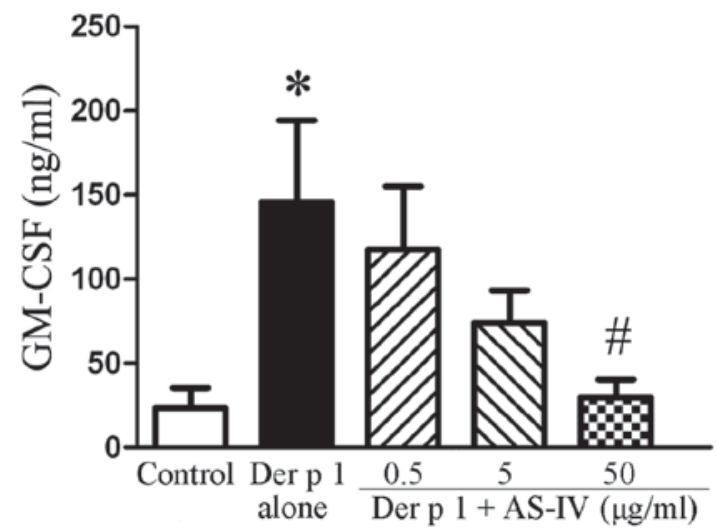

B

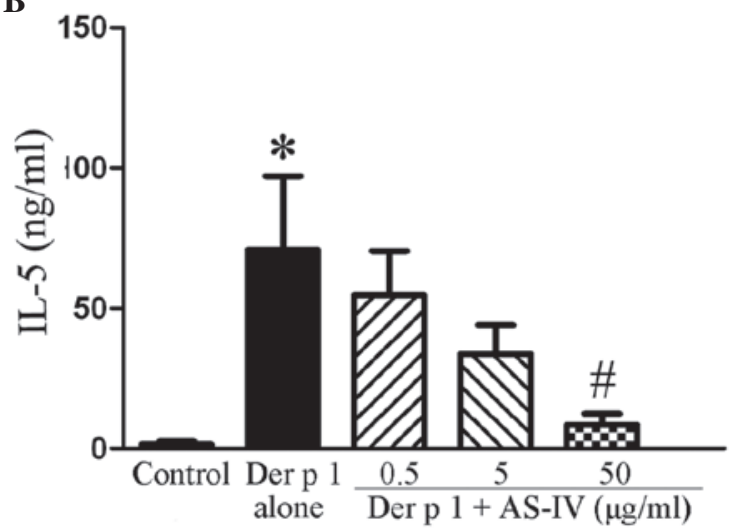

D

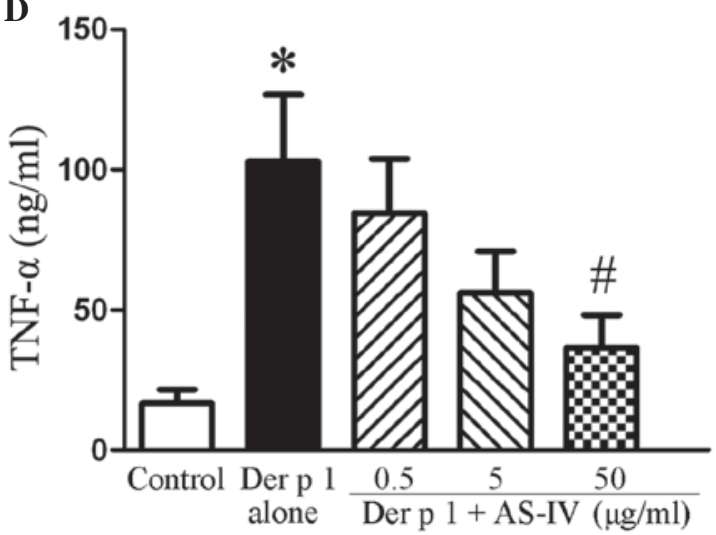

Figure 3. Effect of increasing the concentrations of AS-IV on the Der p 1-induced release of (A) IL-1 $\beta$ (B) IL-5, (C) GM-CSF and (D) TNF- $\alpha$ by eosinophils. Data are presented as the mean \pm SEM from five independent experiments. ${ }^{*} \mathrm{P}<0.05 ;{ }^{*} \mathrm{P}<0.01 \mathrm{vs}$. control cells or Der $\mathrm{p} 1$-stimulated cells. AS-IV, astragaloside IV; Der p 1, Dermatophagoides pteronyssinus 1; IL, interleukin; GM-CSF, granulocyte macrophage colony stimulating factor; TNF, tumor necrosis factor. 
A

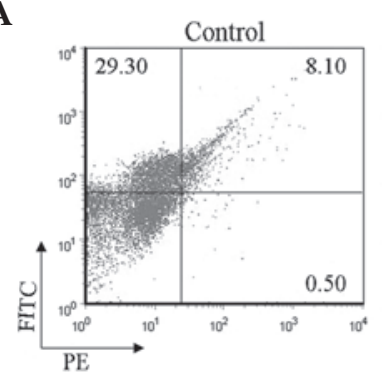

B

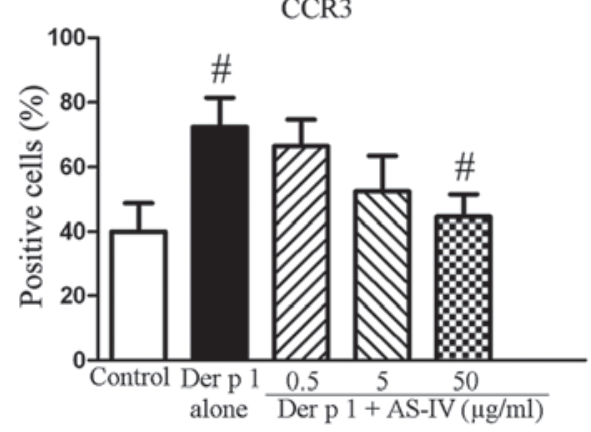

Der p $1+$ AS-IV $(\mu \mathrm{g} / \mathrm{ml})$
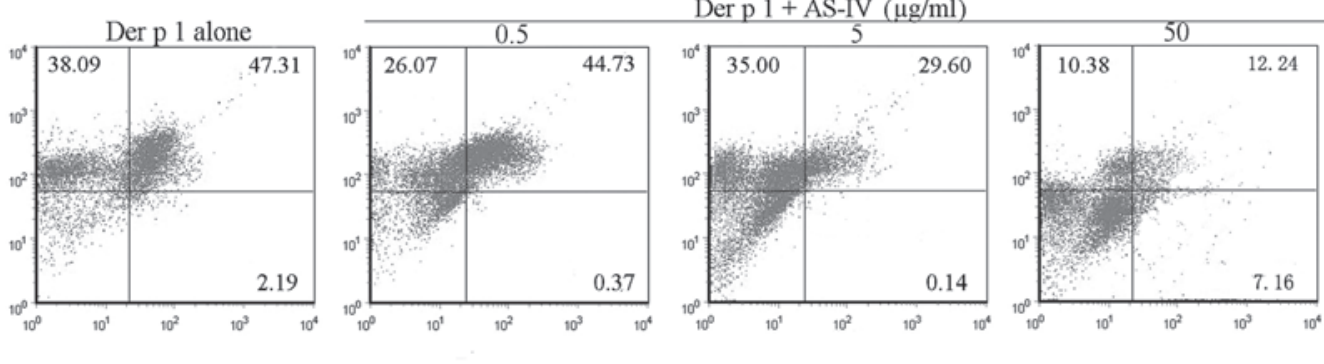

Figure 4. Effect of increasing concentrations of AS-IV on the Der p 1-induced surface expression of CCR3 and ICAM-1 by eosinophils. (A) Flow cytometric analysis was used to determine the expression of CCR3 (FITC) and ICAM-1 (PE) (representative of five independent experiments). (B) Statistical analysis of CCR3 and ICAM-1 expression. Data are presented as the mean \pm SEM from five independent experiments. ${ }^{*} \mathrm{P}<0.01$; ${ }^{\#} \mathrm{P}<0.05$ vs. control cells or Der $\mathrm{p}$ 1-stimulated cells. AS-IV, astragaloside IV; Der p 1, Dermatophagoides pteronyssinus 1; CCR3, CC chemokine receptor 3; ICAM-1, intercellular adhesion molecule-1; FITC, fluorescein isothiocyanate; PE, phycoerythrin.

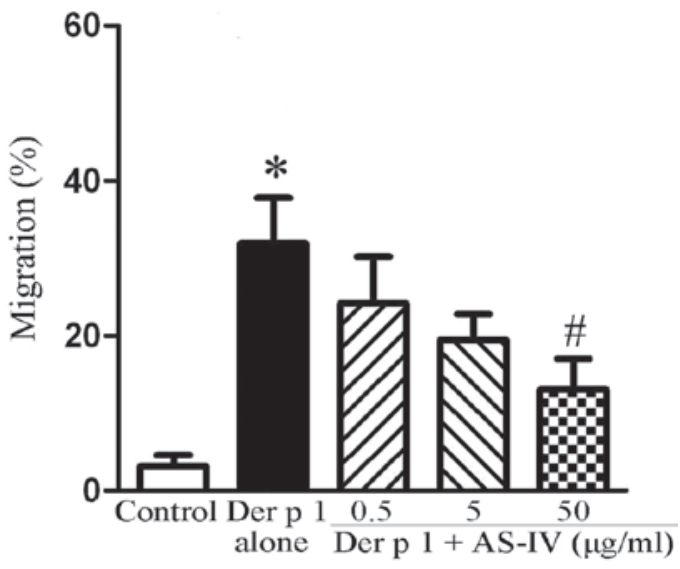

Figure 5. Effect of increasing concentrations of AS-IV on the Der p 1-induced TEM of eosinophils. Data are presented as the mean \pm SEM of five independent experiments. ${ }^{*} \mathrm{P}<0.01$; ${ }^{\#} \mathrm{P}<0.05$ vs. control cells or Der $\mathrm{p} 1$-stimulated cells. AS-IV, astragaloside IV; Der p 1, Dermatophagoides pteronyssinus 1 ; TEM, transendothelial migration.

expression of CCR3 and ICAM-1 by eosinophils $(\mathrm{P}<0.05)$ (Fig. 4). However, pretreatment with increasing concentrations of AS-IV attenuated Der p 1-induced CCR3 and ICAM-1 expression. The inhibition was statistically significant at an AS-IV concentration of $50 \mu \mathrm{g} / \mathrm{ml}(\mathrm{P}<0.05)$.

AS-IV regulates the Der $p$ 1-induced transmigration of eosinophils. Transendothelial chemotaxis has been established as an in vitro model of leukocyte migration across postcapillary venules. This assay allows the quantitative evaluation of the effect of AS-IV on the selective transmigration of eosinophils in response to the Der $\mathrm{p} 1$ allergen. Low levels of TEM were found in the absence of Der p 1 (Fig. 5). By contrast, stimulation with Der $\mathrm{p} 1$ resulted in significant TEM, although the actual percentage of eosinophils that migrated in response to Der $\mathrm{p} 1$ was lower in the assay with an endothelial cell layer than in that performed without endothelial cells (data not shown). The pretreatment of eosinophils with increasing concentrations of AS-IV resulted in the concentration-dependent inhibition of migration following the activation of cells. We also found that inhibition was statistically significant at $50 \mu \mathrm{g} / \mathrm{ml}$ AS-IV $(\mathrm{P}<0.05)$.

\section{Discussion}

In this study, we confirmed that Der $\mathrm{p} 1$ activates eosinophils at several levels, including prolonging survival, upregulating the surface molecule expression and promoting the secretion of cytokines and migration. In addition, we demonstrated that AS-IV inhibits the activation and migration of eosinophils in response to Der $\mathrm{p} 1$. The migration and activation of eosinophils are involved in the development of allergic asthma $(1,2)$. The blockade of these processes by AS-IV, as reported in the present study, clarifies the mechanism underlying our previously published results that AS-IV reduces the number of eosinophils in lung tissue and bronchoalveolar lavage and decreases airway hyperresponsiveness (15).

As the life span of eosinophils is as short as 4 days, prolonged survival at the sites in which eosinophils have migrated is essential for the cells to function. Notably, the apoptosis of eosinophils in vivo resolves airway inflammation in asthma (20). Using an in vitro model, the present study addressed the hypothesis that that Der $\mathrm{p} 1$ significantly 
promotes the survival of eosinophils. In addition, we found that AS-IV, at a concentration of $50 \mu \mathrm{g} / \mathrm{ml}$, markedly decreased cell survival, establishing the clear proapoptotic effect of this drug on stimulated eosinophils.

Activated eosinophils are capable of releasing a variety of pro-inflammatory cytokines, including IL-3, IL-4, IL-5, IL-6, TNF- $\alpha$ and GM-CSF, which are believed to contribute to the pathophysiology of the underlying inflammatory disorders. The overproduction of survival factors, including IL-5, TNF- $\alpha$ and GM-CSF, is known to be correlated with the delayed apoptosis of eosinophils, leading to the accumulation of these cells in inflamed tissues (21). In the present study, we observed that Der $\mathrm{p} 1$ significantly activated eosinophils to secrete IL-1 $\beta$, IL-5, TNF- $\alpha$ and GM-CSF, confirming and extending previous findings (10). We also found that the pretreatment of eosinophils with AS-IV $(50 \mu \mathrm{g} / \mathrm{ml})$ largely eliminated the Der $\mathrm{p} 1$-induced release of IL-1 $\beta, \mathrm{IL}-5, \mathrm{TNF}-\alpha$ and GM-CSF. Our results therefore indicate that one of the mechanisms by which AS-IV reduces eosinophil numbers in the allergic airway is the decreased levels of these cytokines and the increased apoptosis of eosinophils.

Flow cytometric analysis confirmed previous findings that Der $\mathrm{p} 1$ induces the expression of ICAM-1 and CCR 3 by eosinophils $(9,10)$. NF- $\kappa \mathrm{B}$ has been suggested to be involved in the Der $\mathrm{p}$ 1-induced expression of ICAM-1 and CCR3 by eosinophils. Certain studies have reported that the pretreatment of human eosinophilic leukemia cells with an NF- $\kappa \mathrm{B}$ inhibitor (MG-132) significantly inhibited the ICAM-1 expression promoted by the HDM extract (9) and the inhibition of $\mathrm{NF}-\kappa \mathrm{B}$ signaling by the expression of a transdominant mutant of $\mathrm{I} \kappa \mathrm{B} \alpha$ resulted in the almost complete blockade of the TNF- $\alpha$-induced expression of CCR3 in NIH3T3 fibroblasts (22). Therefore, NF- $\kappa \mathrm{B}$ dysregulation may be critical in mediating the expression of ICAM-1 and CCR3. Notably, our results have shown that pretreatment with $50 \mu \mathrm{g} / \mathrm{ml}$ AS-IV also inhibited the induction of ICAM-1 and CCR3 by Der $p$ 1. A possible explanation of this observation is that AS-IV possesses anti-inflammatory activity via the inhibition of the $N F-\kappa B$ pathway (23). NF- $\kappa$ B activation is necessary for the generation of soluble mediators and adhesion protein expression, which controls the survival $(21,24)$, effector functions $(10,11)$ and recruitment $(25)$ of cells.

The migration of eosinophils into specific tissues is a hallmark of allergic disease. The generation of inflammatory mediators in response to tissue injury or inflammation results in leukocyte chemotaxis and migration (26). Both ICAM-1 (4) and CCR3 $(6,7)$ are crucial for the accumulation of eosinophils during an allergic reaction. The blockade of ICAM-1 (27) or CCR3 (28) by neutralizing mAb inhibits the recruitment of eosinophils. In the present study, we employed a transendothelial chemotaxis assay to evaluate the effect of AS-IV on the selective transmigration of eosinophils in response to the Der p 1 allergen. As expected, preincubation with AS-IV eliminated the migratory response of eosinophils to Der $\mathrm{p} 1$. These observations suggest that AS-IV exerts its inhibitory effect on the Der p 1-induced TEM of eosinophils through the attenuated expression of CCR3 and ICAM-1. However, more studies are required to elucidate the intracellular signaling mechanisms by which AS-IV regulates the HDM-mediated activation and migration of eosinophils.
In conclusion, AS-IV is capable of inhibiting the prolonged survival, elevated secretion of cytokines and transmigration of eosinophils induced by the Der $\mathrm{p} 1$ allergen. Thus, AS-IV may be a natural therapeutic medicine with a role in the prevention of a range of atopic inflammatory conditions, including asthma, that are characterized by eosinophilia.

\section{Acknowledgements}

The authors wish to thank Dr Saiying Chen for her assistance in the isolation of eosinophils.

\section{References}

1. Huang M, Liu X, Du Q, et al: Inhibitory effects of sunitinib on ovalbumin-induced chronic experimental asthma in mice. Chin Med J (Engl) 122: 1061-1066, 2009.

2. Rose CE Jr, Lannigan JA, Kim P, et al: Murine lung eosinophil activation and chemokine production in allergic airway inflammation. Cell Mol Immunol 7: 361-374, 2010.

3. Walsh GM, Al-Rabia M, Blaylock MG, et al: Control of eosinophil toxicity in the lung. Curr Drug Targets Inflamm Allergy 4: 481-486, 2005.

4. Tang ML and Fiscus LC: Important roles for L-selectin and ICAM-1 in the development of allergic airway inflammation in asthma. Pulm Pharmacol Ther 14: 203-210, 2001.

5. Ferland C, Flamand N, Davoine F, Chakir J and Laviolette M: IL-16 activates plasminogen-plasmin system and promotes human eosinophil migration into extracellular matrix via CCR3-chemokine-mediated signaling and by modulating CD4 eosinophil expression. J Immunol 173: 4417-4424, 2004.

6. Ok IS, Kim SH, Kim BK, Lee JC and Lee YC: Pinellia ternata, Citrus reticulata, and their combinational prescription inhibit eosinophil infiltration and airway hyperresponsiveness by suppressing CCR3+ and Th2 cytokines production in the ovalbumin-induced asthma model. Mediators Inflamm 413270 , 2009.

7. Mori A, Ogawa K, Someya K, et al: Selective suppression of Th2-mediated airway eosinophil infiltration by low-molecular weight CCR3 antagonists. Int Immunol 19: 913-921, 2007.

8. Busse WW and Rosenwasser LJ: Mechanisms of asthma. J Allergy Clin Immunol 111: S799-S804, 2003.

9. Kwon BC, Sohn MH, Kim KW, et al: House dust mite induces expression of intercellular adhesion molecule-1 in EoL-1 human eosinophilic leukemic cells. J Korean Med Sci 22: 815-819, 2007.

10. Wong CK, Li MLY, Wang CB, et al: House dust mite allergen Der $\mathrm{p} 1$ elevates the release of inflammatory cytokines and expression of adhesion molecules in co-culture of human eosinophils and bronchial epithelial cells. Int Immunol 18: 1327-1335, 2006.

11. Coward WR, Sagara H, Wilson SJ, et al: Allergen activates peripheral blood eosinophil nuclear factor- $\kappa \mathrm{B}$ to generate granulocyte macrophage-colony stimulating factor, tumor necrosis factor- $\alpha$, and interleukin-8. Clin Exp Allergy 4: 1071-1078, 2004.

12. Pichavant M, Charbonnier AS, Taront S, et al: Asthmatic bronchial epithelium activated by the proteolytic allergen Der p 1 increases selective dendritic cell recruitment. J Allergy Clin Immunol 115: 771-778, 2005.

13. Chou DL, Daugherty BL, McKenna EK, et al: Chronic aeroallergen during infancy enhances eotaxin-3 expression in airway epithelium and nerves. Am J Respir Cell Mol Biol 33: 1-8, 2005.

14. Kay AB: The role of eosinophils in the pathogenesis of asthma. Trends Mol Med 11: 148-152, 2005.

15. Du Q, Chen Z, Zhou LF, et al: Inhibitory effects of astragaloside IV on ovalbumin-induced chronic experimental asthma. Can J Physiol Pharmacol 86: 449-457, 2008.

16. Yuan X, Sun S, Wang S and Sun Y: Effects of Astragaloside IV on IFN-gamma level and prolonged airway dysfunction in a murine model of chronic asthma. Planta Med 77: 328-333, 2011.

17. Bateman ED, Hurd SS, Barnes PJ, et al: Global strategy for asthma management and prevention: GINA executive summary. Eur Respir J 31: 143-178, 2008.

18. Muller WA, Ratti CM, McDonnell SL and Cohn ZA: A human endothelial cell-restricted, externally disposed plasmalemmal protein enriched in intercellular junctions. J Exp Med 170: 399-414, 1989. 
19. Nagata M, Saito K, Kikuchi I, et al: Effect of the cysteinyl leukotriene antagonist pranlukast on transendothelial migration of eosinophils. Int Arch Allergy Immunol 137 (Suppl 1): 2-6, 2005.

20. Maret M, Ruffié C, Létuvé S, et al: A role for Bid in eosinophil apoptosis and in allergic airway reaction. J Immunol 182: 5740-5747, 2009.

21. Martinez-Losa M, Cortijo J, Juan G, et al: Modulatory effects of $\mathrm{N}$-acetyl-L-cysteine on human eosinophil apoptosis. Eur Respir J 30: 436-442, 2007.

22. Huber MA, Denk A, Peter RU, et al: The IKK-2/IкB $\alpha / \mathrm{NF}-\kappa \mathrm{B}$ pathway plays a key role in the regulation of CCR3 and eotaxin-1 in fibroblasts. A Critical link to dermatitis in IкB $\alpha$-deficient mice. J Biol Chem 277: 1268-1275, 2002.

23. Zhang WJ, Hufnagl P, Binder BR and Wojta J: Antiinflammatory activity of astragaloside IV is mediated by inhibition of NF- $\mathrm{KB}$ activation and adhesion molecule expression. Thromb Haemost 90: 904-914, 2003.
24. Gu XY,Zhou LF, Zhang MS, et al: Targeted NF-кB inhibition of asthmatic serum-mediated human monocyte-derived dendritic cell differentiation in a transendothelial trafficking model. Cell Immunol 260: 14-20, 2009.

25. Rothenberg ME and Hogan SP: The eosinophil. Annu Rev Immunol 24: 147-174, 2006.

26. Medzhitov R: Origin and physiological roles of inflammation. Nature 454: 428-435, 2008

27. Forbes E, Hulett M, Ahrens R, et al: ICAM-1-dependent pathways regulate colonic eosinophilic inflammation. J Leukoc Biol 80: 330-341, 2006.

28. Chuang CC, Su KE, Chen CW, et al: Anti-CCR3 monoclonal antibody inhibits eosinophil infiltration in Angiostrongylus cantonensis-infected ICR mice. Acta Trop 113: 209-213, 2010. 